\title{
O PENSAMENTO CRÍTICO PODE SER FOMENTADO POR MUSEUS ATRAVÉS DO USO DE REDES SOCIAIS? E ISSO PODE SER MENSURADO? *
}

\author{
Irene Rubino \\ Katherine Nowak \\ Amy Martinez \\ Hanna Hipp \\ Giuseppe Monaco ** \\ Smithsonian Center for Learning and Digital Access
}

\section{RESUMO:}

Com o crescimento do uso de ferramentas de cyber-aprendizagem (cyber-learning) por parte dos museus para envolver seus públicos-alvo, permanecem questões sobre o efeito dessas ferramentas sobre o pensamento crítico e a interação dos participantes.Apesar da existência de pesquisas sobre a que extensão o pensamento crítico é fomentado em ambientes formais de cyber-aprendizagem, há uma falta de pesquisas em ambientes informais de cyber-aprendizagem, como conferências virtuais. $O$ objetivo do projeto era avaliar se o pensamento crítico poderia ser mensurado em conferências virtuais e em eu medida ele poderia ser estimulado. Uma abordagem de métodos mistos avaliando a logística de participação e a análise de conversas revelou que, embora o pensamento crítico tenha sido estimulado durante as conferências virtuais, apenas as primeiras fases, como a identificação e definição de problemas, foram utilizadas pelos participantes. As fases superiores do pensamento crítico, a exploração de problemas, a aplicação e a integração não foram muito utilizadas durante as conferências virtuais. $\bigcirc$ estudo também confirmou o papel crucial do moderador na facilitação da participação.

\section{PALAVRAS-CHAVES:}

cyber-aprendizagem;pensamento crítico; conferências virtuais.

\begin{abstract}
:
As museums more frequently employ cyberlearning tools to engage target audiences, questions are left as to the effect they have on critical thinking and participant interaction. While research exists regarding the extent to which critical thinking is stimulated in formal cyber-learning environments, studies related to informal cyber-learning environments, such as virtual conferences, are lacking. The scope of this project was to evaluate whether critical thinking could be assessed in virtual conferences and the extent to which it could be stimulated. A mixed- method approach, evaluating participation logistics and conversation analysis, revealed that, while critical thinking was stimulated during the virtual conferences, mostly the less complex stages, - such as problem identification and definition-were observed. More complex stages — such as problem exploration, application, and integration-were not as commonly observed. The study also confirmed the crucial role of the moderator in facilitating participation.
\end{abstract}

\section{KEY-WORDS:}

cyber-learning; critical thinking; virtual conferences.

\footnotetext{
*Tradução do artigo original:Ana Lúcia de Abreu Gomes. Revisão:Adriana Mortara Almeida.

* Smithsonian Center for Learning and Digital Access, Washington, D.C., EUA. Correspondências devem ser endereçadas a Giuseppe Monaco (monacop@si.edu).
} 


\section{Introdução}

A nova fronteira educacional no contexto global do século $X X I$ é representada pela cyber-aprendizagem (cyber-learning - CL), definida como "o uso de computação em rede e tecnologias de comunicação para apoiar a aprendizagem" (National Science Foundation, 2008). Muitas instituições culturais atualmente se aproveitam das novas tecnologias para desenvolver e promover novas oportunidades de aprendizagem ao seu público-alvo. Incluídas no espectro das iniciativas de CL, as Conferências Virtuais (Virtual Conferences - VCs) são um método adotado recentemente por museus para disseminar informação e envolver o público-alvo. Apesar de as instituições de aprendizagem formal, como as universidades, virem utilizando extensivamente cursos de aprendizagem à distância e ferramentas de CL da Web 2.0, museus e outras organizações que oferecem oportunidades de aprendizagem informal começaram a trilhar mais recentemente esse caminho (Lopez et al., 2010). Ademais, embora a maior parte da atenção e do apoio econômico tenha sido concentrada, até agora, na criação de infraestruturas de $C L$, sabe-se pouco sobre que tipo de aprendizagem ocorre com seu uso. A pesquisa nessa área pode levar ao aperfeiçoamento nas $C L$ oferecidas por museus (Di Blas \& Poggi, 2006).

Descobertas recentes de avaliações de iniciativas de CL em ambientes de aprendizagem formal demonstraram que a obtenção dos resultados propostos de aprendizagem por meio de experiências cibernéticas colaborativas depende grandemente de uma série de variáveis, como as motivações e características dos participantes, e o design e a facilitação instrucionais (Curran et al., 2003; Hara et al., 2000; McKenzie e Murphy, 2000). Normalmente, esses estudos usaram amostragens pequenas de dados sem análises estatísticas. Nos últimos anos, um dos resultados mais desejados por iniciativas de educação superior e de desenvolvimento profissional é o pensamento crítico (Garrison, 1992; Garrison, 1991; Brookfield, 1987). O pensamento crítico foi definido de formas variadas por diferentes autores ao longo dos anos (Brookfield, 1987; McPeck, I98I; D’Angelo, I97I; Dewey, 1933). Contudo, o principal conceito que advém de uma visão geral da literatura é de que o pensamento crítico (critical thinking - CT) pode ser considerado um processo cognitivo interno profundo, uma forma proativa de pensamento que tem como objetivo a compreensão das experiências por meio da análise e julgamento de questões e informações, sem a realização de presunções. Como ressaltado por D. R. Garrison, o processo de CT pode ser concebido como um ciclo de atividades de pensamento. Mais especificamente, o autor identifica cinco estágios no processo de CT: Identificação do Problema; Definição do Problema; Exploração do Problema; Aplicação do Problema; e Integração do Problema (Garrison, 1991).

Segundo o modelo holístico de Garrison, a validação do significado construído pelo aprendiz ocorre por meio de ação comunicativa, ou, em outras palavras, por meio do compartilhamento de interpretações pessoais com os outros (Garrison, 1991). Em ambientes de aprendizagem formal, acadêmicos investigaram até que ponto o CT pode ser desenvolvido por meio de oportunidades de aprendizagem online, com a utilização da análise de conteúdos e discursos de conversas/postagens escritas (Bai, 2009; Perkins \& Murphy, 2006; Maurino, 2006; Curran et al., 2003; Bullen, 1998; Newman et al., 1996; Gunawardena et al., 1997; Henri, 1992). Contudo, estudos desse tipo ainda são escassos quando se trata de ambientes informais de aprendizagem. Dentro desse quadro conceitual (Figu- 
ra I) e das áreas gerais de pesquisa descritas anteriormente, a principal questão que este estudo deseja abordar é: o pensamento crítico pode ser mensurado em um ambiente de cyber-aprendizagem como as VCs? Dentro dessa questão, há ainda esta:Até que ponto o CT pode ser estimulado por meio da participação em VCs em uma situação informal de aprendizagem? Ademais, considerando que outros autores indicaram que a profundidade do pensamento pode ser influenciada pelo nível das questões direcionadas aos participantes durante os eventos online (Bai, 2009; MacKnight, 2009; Hara et al., 2000; Bullen, 1998), uma subsequente questão de pesquisa é: Diferentes tipos de apresentações nas conferências gerariam níveis mensuravelmente diferentes de pensamento crítico entre os participantes?

O objetivo desta pesquisa tem natureza dupla: por um lado, busca fornecer informação que auxiliaria na conceituação e implementação de futuras VCs mais eficazes. Por outro, ela busca fornecer uma perspectiva original ao mundo emergente dos ambientes informais de aprendizagem e às novas tecnologias, além do desenvolvimento de novas competências, com referência especial ao papel educacional dos museus hoje.

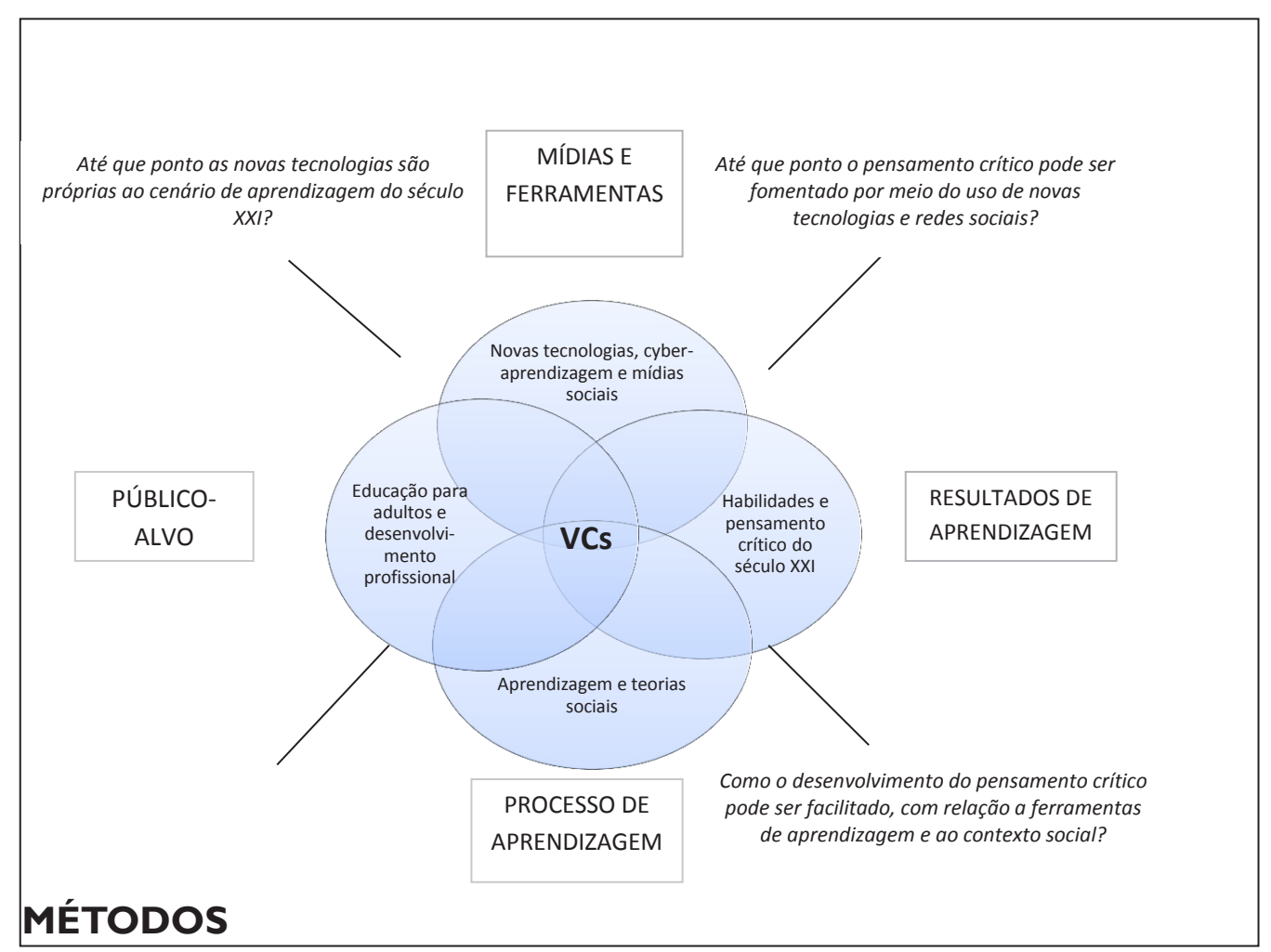

\section{Contexto da pesquisa}

O Smithsonian Center for Learning and Digital Access (Centro do Smithsonian para Aprendizagem e Acesso Digital - SCLDA) organiza VCs desde fevereiro de 2009. As VCs foram originalmente concebidas como um meio de desenvolvimento profissional para professores. Contudo, uma pesquisa online realizada com as pessoas que participaram da primeira VC ("Abraham Lincoln", fevereiro de 2009) demonstrou que mais da metade dos participantes não eram professores. Eram estudantes ou profissionais de outras áreas. Consequentemente, o SCLDA implementou as duas VCs examinadas neste trabalho - deno- 
minadas "Mudanças Climáticas" e "Solução de Problemas com Especialistas do Smithsonian" -, com vistas a esse público muito mais amplo. A matrícula para esses eventos online era grátis e aberta a todos.

As VCs tinham a forma de eventos online, acessíveis por meio de uma página específica do Smithsonian Institution (SI) (http://www.smithsonianconference.org/). $O$ formato online em tempo real foi escolhido não somente para alcançar os professores e pessoas interessadas nos temas propostos, independente de sua localização geográfica, mas também para criar uma oportunidade para que interajam em tempo real com especialistas do SI e se conectem a outras pessoas com os mesmos interesses.

Durante cada VC, especialistas do Smithsonian abordavam um tópico específico por meio de uma palestra virtual multimídia, envolvendo áudio, vídeos e slides. Um moderador estava sempre presente para facilitar a discussão entre os especialistas e os usuários conectados, encorajando a participação através de perguntas escritas e orais.

Ferramentas interativas permitiam a participação ativa da audiência: uma Janela de Chat para Perguntas \& Respostas (Chat ( $Q$ \& A)) estava disponível permanentemente durante cada sessão, enquanto uma segunda janela de chat surgia em momentos específicos para estender as oportunidades de interação ao sugerir discussões adicionais (Figura 2). Os participantes podiam utilizar essas janelas para escrever mensagens destinadas ao palestrante, ao moderador e/ou às outras pessoas que assistiam a conferência'. As postagens eram filtradas pelo moderador. Janelas pop-up com pesquisas de opinião, destinadas a coletar as opiniões dos participantes, também eram utilizadas.

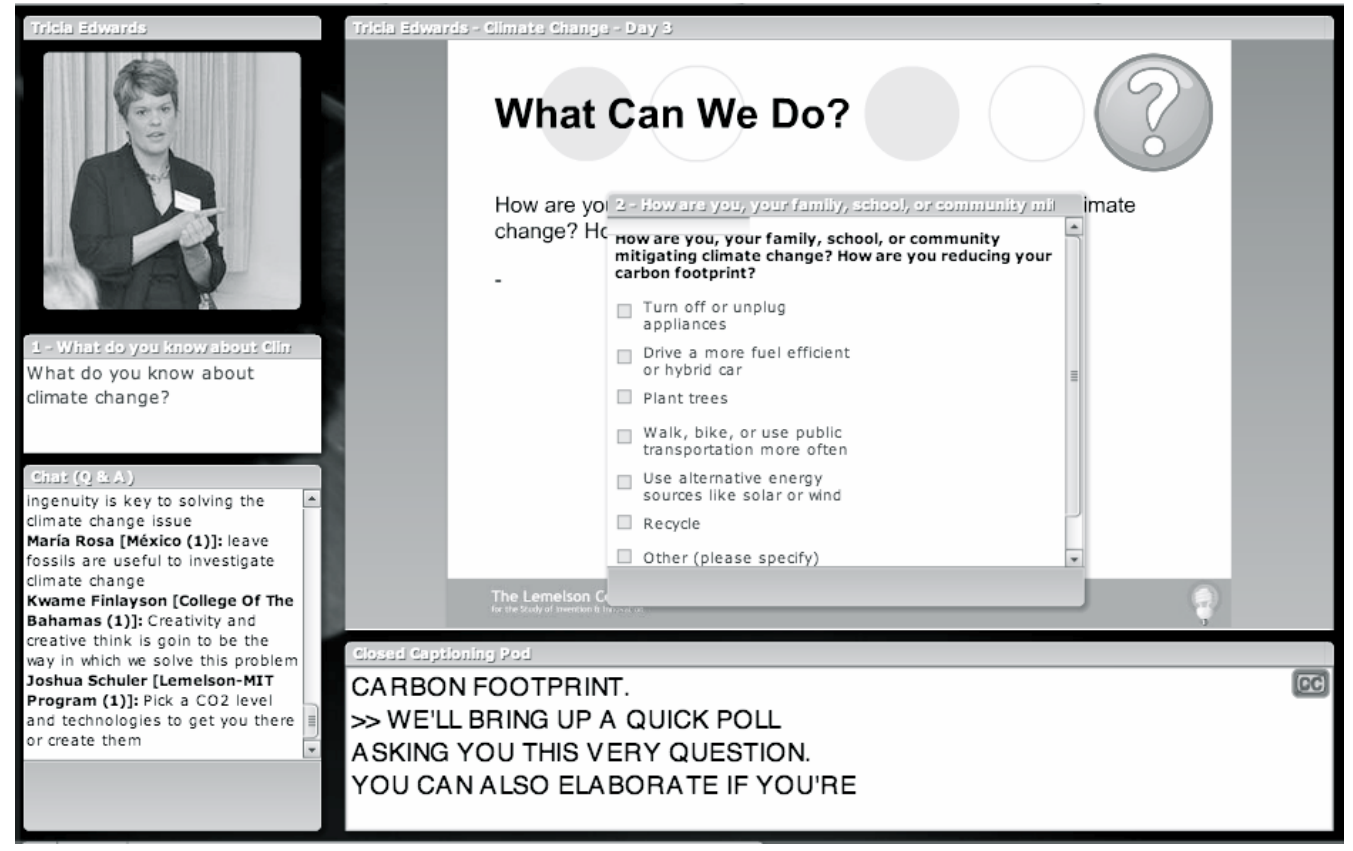

Figura 2. Ambiente interativo fornecido durante as Conferências Virtuais do SCLDA

I A Comunicação Mediada por Computador (Computer Mediated Communication - CMC) possibilitada por essas ferramentas pode ser definida como quasi-síncrona, o que significa que as mensagens eram compostas pelos participantes antes da transmissão, mas que seriam primeiramente filtradas pelo moderador da conferência e, por fim, visualizadas. As mensagens apareciam na tela em ordem cronológica, com uma indicação de seu autor ao lado da mensagem digitada.A CMC definida como comunicação assíncrona - que será citada frequentemente no texto - permite aos usuários postar e ler mensagens a qualquer hora, sem a necessidade dos remetentes e destinatários estarem online simultaneamente para que a comunicação ocorra. 
Ademais, recursos educacionais e ideias para atividades a serem conduzidas antes e depois das VCs eram disponibilizados na página da internet para permitir que os participantes aprofundassem sua experiência de VC e a ligassem a interesses pessoais e à vida cotidiana.

AVC "Mudanças Climáticas" foi realizada em três dias, de 29 de setembro a $I^{\circ}$ de outubro de 2009. Em cada dia havia quatro sessões educacionais de cinquenta e cinco minutos - chamadas Evidências, Impacto, Respostas e Sessão Especial - lideradas por profissionais do Smithsonian, em um total de doze sessões (http://www.smithsonianconference.org/climate/). Cada dia, o tema era analisado a partir de diferentes perspectivas.

A VC "Solução de Problemas com os Especialistas do Smithsonian" ocorreu em quatro dias, 13 e 14 e 28 e 29 de abril de 2010 . Cada dia tinha um tema diferente - Entendendo a Experiência Americana,Valorizando Culturas Mundiais, Desvendando os Mistérios do Universo e Entendendo e Sustentando um Planeta Diverso -, que era explorado em três sessões diferentes de cinquenta minutos, com um total de doze sessões (http://www.smithsonianconference.org/expert/).

\section{A Matriz de Avaliação: coletando e codificando os dados}

Com suas raízes na teoria construtivista (Vygotski, 1978; Caffarella e Merriam, 1999; Kelly, 2009), este estudo adotou uma abordagem de metodologias mistas e considerou somente as mensagens postadas nas Janelas de Chat para Perguntas e Respostas como objeto de pesquisa. Para estruturar a pesquisa, uma matriz de avaliação foi desenvolvida, levando em conta duas amplas áreas de análise: logística e análise de conversas (Figura 3).

\begin{tabular}{|c|c|c|c|c|}
\hline \multicolumn{5}{|c|}{ LOGÍSTICA } \\
\hline \multicolumn{4}{|c|}{ Taxa de Participação } & Tipo de Participação \\
\hline $\begin{array}{l}\mathrm{n}^{\circ} \text { de participantes conec- } \\
\text { tados }\end{array}$ & $\begin{array}{l}\mathrm{n}^{\circ} \text { de parti- } \\
\text { cipantes que } \\
\text { postaram }\end{array}$ & $\begin{array}{c}\mathrm{n}^{\circ} \text { de pos- } \\
\text { tagens }\end{array}$ & $\begin{array}{l}\text { Tipo de Comen- } \\
\text { tário } \\
\text { Frase (I) } \\
\text { Orações (2) } \\
\text { Uma palavra (3) } \\
\text { Combinação (4) } \\
\text { Pontuação/Símbo- } \\
\text { lo (5) } \\
\text { Não aplicável (6) }\end{array}$ & $\begin{array}{l}\text { Administrativo (I) } \\
\text { Técnico (2) } \\
\text { Social (3) } \\
\text { Conteúdo (4) } \\
\text { Combinação Social/Conteúdo (5) } \\
\text { Não aplicável (6) }\end{array}$ \\
\hline \multicolumn{5}{|c|}{ ANALISE DE CONVERSAS } \\
\hline \multicolumn{4}{|c|}{ Interação } & Pensamento Crítico \\
\hline $\begin{array}{l}\text { Explícita: Resposta Direta (I) } \\
\text { Explícita: Comentário Direto } \\
\text { (2) } \\
\text { Implícita: Resposta Indireta (3) } \\
\text { Implícita: Comentário Indi- } \\
\text { reto (4) } \\
\text { Independente (5) } \\
\text { Não Aplicável (6) }\end{array}$ & $\begin{array}{l}\text { Apresentador par } \\
\text { pante (I) } \\
\text { Participante para } \\
\text { (2) } \\
\text { Participante para } \\
\text { dor (3) } \\
\text { Moderador para } \mathrm{F} \\
\text { tes (4) } \\
\text { Participantes para } \\
\text { dor (5) } \\
\text { Moderador para } A \\
\text { dor (6) } \\
\text { Não Aplicável (7) }\end{array}$ & $\begin{array}{l}\text { Partici- } \\
\text { articipante } \\
\text { articipan- } \\
\text { Modera- } \\
\text { presenta- }\end{array}$ & $\begin{array}{l}\text { Postagem origi- } \\
\text { nal (I) } \\
\text { Resposta (2) }\end{array}$ & $\begin{array}{l}\text { Clarificação Elementar/ldentificação de Problema } \\
\text { (I) } \\
\text { Clarificação de Profundidade/Definição de Pro- } \\
\text { blema (2) } \\
\text { Inferência/Exploração de Problema (3) } \\
\text { Julgamento/Aplicação de Problema (4) } \\
\text { Estratégia/ Integração de Problemas (5) } \\
\text { Não Aplicável (6) }\end{array}$ \\
\hline
\end{tabular}

Figura 3. Logística 


\section{Matriz de Avaliação}

Tanto a logística quanto a análise de conversas foram organizadas em duas dimensões principais (Taxa de Participação/Tipo de Participação e Tipo de Interação/Pensamento Crítico, respectivamente). Cada dimensão possuía várias subdimensões que foram analisadas com referência a diferentes categorias.

Logística. Para se ter uma visão geral da taxa de participação na iniciativa de VCs, foram coletados dados quantitativos. Em particular, as VCs eram analisadas segundo as seguintes categorias: número de pessoas conectadas, número de participantes que postavam e número total de mensagens.

Ao lado da análise, cada postagem era codificada de acordo com o tipo do comentário: I) frase - definida como uma postagem de várias palavras que não é uma oração; 2) oração - definida como uma postagem com sujeito, verbo e predicado; 3) postagem uma palavra; 4) combinação de outras categorias; 5) pontuação/símbolo; 6) não aplicável. $O$ número de orações por postagem também foi registrado. $O$ tipo de participação foi codificado com uma adaptação das categorias desenvolvidas por McKenzie \& Murphy (2000): I) administrativa; 2) técnica; 3) social; 4) conteúdo; 5) combinação social/conteúdo; 6) não aplicável.

Ademais, deve-se notar que as categorias administrativa e técnica foram incluídas à lista de codificação, mas que esse tipo de mensagens era filtrado durante a sessão: com poucas exceções, postagens relativas a esse tipo de informação estavam indisponíveis nas transcrições, e em sua maioria não foram codificadas. Contudo, deve-se ressaltar que, dado o objetivo geral desta pesquisa - a mensuração do pensamento crítico através das VCs - esses dados ausentes não afetam a validade do estudo.

Análise de Conversas.A interação nas discussões online foi investigada por meio de análise de cada postagem, com enfoque na interação entre os participantes e nos tipos de interação.

A interação entre os participantes descreve o processo de transmissão da mensagem de acordo com o papel desempenhado pelo remetente e o destinatário pretendido dentro da conferência como um todo. Por exemplo, as categorias utilizadas na codificação são: I) Apresentador para Participante; 2) Participante para Participante; 3) Participante para Apresentador; 4) Moderador para Participantes; 5) Participante para Moderador; 6) Moderador para Apresentador; 7) Não Aplicável. O termo "destinatário" é qualificado aqui como “destinatário pretendido/primário”, pois, embora a vasta maioria das postagens tenha sido implicitamente ou explicitamente destinada a um destinatário específico, elas poderiam, mesmo assim, ser lidas por todos que participavam do evento online ("destinatários secundários").

O tipo de interação foi explorado de acordo com as categorias identificadas por Henri (1992) para a análise de discussões online: I) Explícita: Resposta Direta; 2) Explícita: Comentário Direto; 3) Implícita: Resposta Indireta; 4) Implícita: Comentário Indireto; 5) Independente; 6) Não aplicável. Contudo, suas definições foram adaptadas ao contexto específico desta pesquisa, isto é, um ambiente de comunicação quasi-síncrona (Tabela I). 


\begin{tabular}{|c|c|c|}
\hline \multicolumn{3}{|c|}{ ANÁLISE DE CONVERSAS:TIPO DE INTERAÇÃO } \\
\hline CATEGORIA & DEFINIÇÃO & EXEMPLO \\
\hline Explícita: Resposta Direta & Response to a question posed & $\begin{array}{l}\text { "In response to your ques- } \\
\text { tion..." }\end{array}$ \\
\hline $\begin{array}{l}\text { Explícita: Comentário Di- } \\
\text { reto }\end{array}$ & $\begin{array}{l}\text { Commentary on question/state- } \\
\text { ment posed }\end{array}$ & $\begin{array}{l}\text { "Wow, seeing that really drives } \\
\text { the point home" }\end{array}$ \\
\hline Implícita: Resposta Indireta & $\begin{array}{l}\text { Responding to a prior message } \\
\text { and not to the original question }\end{array}$ & $\begin{array}{l}\text { "I think the answer might } \\
\text { be..." }\end{array}$ \\
\hline $\begin{array}{l}\text { Implícita: Comentário Indi- } \\
\text { reto }\end{array}$ & $\begin{array}{l}\text { Commentary on someone else's } \\
\text { message, but without indicating } \\
\text { specifically to which message } \\
\text { the contribution referred }\end{array}$ & "I agree totally" \\
\hline Independente & $\begin{array}{l}\text { Relating to the subject under } \\
\text { discussion, but is not in refer- } \\
\text { ence to a prior contribution }\end{array}$ & $\begin{array}{l}\text { Independent question or state- } \\
\text { ment on the subject matter }\end{array}$ \\
\hline Não Aplicável & Not about the subject & "Thank you" \\
\hline
\end{tabular}

Tabela I.Análise de Conversas:Tipo de Interação

Para identificar a origem da postagem, duas categorias - postagens originais e respostas - foram utilizadas.

Para analisar os diferentes níveis de pensamento crítico que surgiram das discussões online, uma revisão da literatura permitiu estabelecer um quadro de análise que integrava o modelo de cinco estágios proposto por Garrison e as cinco habilidades de raciocínio identificadas por F. Henri. (Garrison, I991; Henri, 1992; Hara et al., 2000; Bullen, 1998) (Tabela 2)

\begin{tabular}{|c|c|}
\hline \multicolumn{2}{|c|}{ ESTÁGIOS E HABILIDADES NO PROCESSO DO PENSAMENTO CRÍTICO } \\
\hline Estágios de CT de Garrison & $\begin{array}{l}\text { Habilidades cognitivas criticas de } \\
\text { Henri }\end{array}$ \\
\hline $\begin{array}{l}\text { 1. Identificação de Problema } \\
\text { A triggering event arouses interest in a problem }\end{array}$ & $\begin{array}{l}\text { Clarificação Elementar } \\
\text { Observing or studying a problem, } \\
\text { identifying its elements, observing their } \\
\text { linkages }\end{array}$ \\
\hline $\begin{array}{l}\text { 2. Definição de Problema } \\
\text { Define problem boundaries, ends and means }\end{array}$ & $\begin{array}{l}\text { Clarificação de Profundidade } \\
\text { Analyzing a problem to understand its } \\
\text { underlying values, beliefs and assump- } \\
\text { tions }\end{array}$ \\
\hline $\begin{array}{l}\text { 3. Exploração de Problema } \\
\text { Ability to see to heart of problem based on deep } \\
\text { understanding of situation }\end{array}$ & $\begin{array}{l}\text { Inferência } \\
\text { Admitting or proposing an idea based } \\
\text { on links to admittedly true propositions }\end{array}$ \\
\hline $\begin{array}{l}\text { 4. Aplicação de Problema } \\
\text { Evaluation of alternative solutions and new ideas }\end{array}$ & $\begin{array}{l}\text { Julgamento } \\
\text { Making decisions, evaluations and criti- } \\
\text { cisms }\end{array}$ \\
\hline $\begin{array}{l}\text { 5. Integração de Problemas } \\
\text { Acting upon understanding to validate knowledge }\end{array}$ & $\begin{array}{l}\text { Estratégias } \\
\text { For application of solution following on } \\
\text { choice or decision }\end{array}$ \\
\hline
\end{tabular}

Tabela 2. Os modelos de raciocínio crítico de Garrison e Henri (de Newman et al., 1996) 
O desenvolvimento de um conjunto de indicadores-chave baseado em exemplos encontrados na literatura existente (Hara et al., 2000; McKenzie \& Murphy, 2000; Henri, 1992) foi essencial para guiar o processo de análise e aumentar a validade e coerência interna da pesquisa (Neuendorf, 2002 apud De Wever et al., 2006). (Tabela 3)

\begin{tabular}{|c|c|c|c|}
\hline 172 & CATEGORIA & INDICATORES CHAVE & DEFINIÇÃO \\
\hline \multirow{5}{*}{ 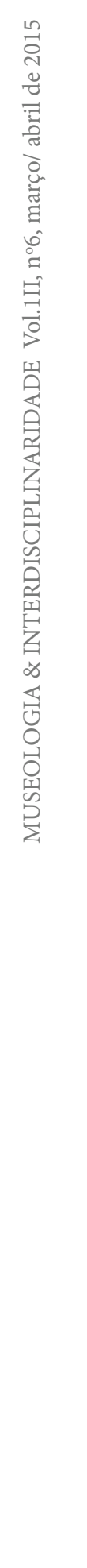 } & $\begin{array}{l}\text { Identificação de Problema } \\
\text { (Garrison)/ } \\
\text { Clarificação Elementar } \\
\text { (Henri) }\end{array}$ & $\begin{array}{ll}\text { - } & \text { List, describe, show, name } \\
\text { - } & \text { One word statement or } \\
\text { - } & \text { Few associations to content } \\
\text { - } & \text { Identifying relevant elements } \\
\text { - } & \text { Reformulating the problem } \\
\text { - } & \text { Asking a relevant question } \\
\text { - } & \text { Identifying previously stated } \\
\text { - } & \text { hypothesis } \\
\text { - } & \text { Inply describing the subject } \\
& \text { Introduce a problem; pose a } \\
\text { question; pass on information } \\
\text { without elaboration }\end{array}$ & $\begin{array}{l}\text { Observing or studying a } \\
\text { problem, identifying its ele- } \\
\text { ments, and observing their } \\
\text { linkages in order to come } \\
\text { to a basic understanding }\end{array}$ \\
\hline & $\begin{array}{l}\text { Definição de Problema / } \\
\text { Clarificação de Profundi- } \\
\text { dade }\end{array}$ & $\begin{array}{ll}\text { - } & \text { Defining the terms } \\
\text { - } & \text { Establishing referential criteria } \\
& \text { Seeking out specialized } \\
\text { - } & \text { information, summarizing } \\
\text { - } & \text { Identify a problem } \\
\end{array}$ & $\begin{array}{l}\text { Analyzing and understanding } \\
\text { a problem to come to an } \\
\text { understanding which sheds } \\
\text { light on the values, beliefs, } \\
\text { and assumptions which } \\
\text { underlie the statement of } \\
\text { the problem }\end{array}$ \\
\hline & $\begin{array}{l}\text { Exploração de Problema / } \\
\text { Inferência }\end{array}$ & $\begin{array}{ll}\text { - } & \text { Explore, experiment, search } \\
\text { - } & \text { Drawing conclusions } \\
\text { - } & \text { Making generalizations } \\
& \text { Formulating a proposition } \\
\text { statements } \\
\text { - Concluding based on evidence } \\
\text { from prior statements; } \\
\text { generalizing }\end{array}$ & $\begin{array}{l}\text { Induction and deduction, ad- } \\
\text { mitting or proposing an idea } \\
\text { on the basis of its link with } \\
\text { propositions already admit- } \\
\text { ted as true }\end{array}$ \\
\hline & $\begin{array}{l}\text { Aplicação de Problema / } \\
\text { Julgamento }\end{array}$ & $\begin{array}{l}\text { - } \begin{array}{l}\text { Apply, build, choose, develop, } \\
\text { evaluate, criticize }\end{array} \\
\text { - Judging the relevance of } \\
\text { solutions } \\
\text { Making value judgments, “I } \\
\text { agree, disagree...” } \\
\text { Expresses a judgment about } \\
\text { an inference, relevance of an } \\
\text { argument, theory or solution } \\
\text { Making decisions, statements, } \\
\text { appreciations, evaluations and } \\
\text { criticisms } \\
\text { Sizing up }\end{array}$ & $\begin{array}{l}\text { Making decisions, state- } \\
\text { ments, appreciations, evalua- } \\
\text { tions and criticism, sizing up }\end{array}$ \\
\hline & $\begin{array}{l}\text { Integração de Problemas / } \\
\text { Estratégia }\end{array}$ & $\begin{array}{l}\text { Proposes a solution; outlines } \\
\text { what is needed to implement } \\
\text { the solution }\end{array}$ & $\begin{array}{l}\text { Proposing co-ordinate actions } \\
\text { for the application of a solu- } \\
\text { tion, or following through on } \\
\text { a choice or a decision }\end{array}$ \\
\hline
\end{tabular}

Tabela 3.Análise de Pensamento Crítico: um conjunto de indicadores-chave (Adaptado e modificado de Hara et al., 2000 e Henri, 1992) 
Caso uma postagem apresentasse vários tipos de comentários refletindo níveis diferentes de CT, ela era classificada segundo o comentário que apresentasse o nível mais avançado de CT.

Fonte de dados e unidade de análise. Primeiramente, as postagens filtradas nas Janelas de Perguntas e Respostas I e 2 (quando presentes) foram obtidas do sistema, transferidas para tabelas em planilhas de excel e relacionadas às questões específicas de apresentadores ou moderadores com a utilização de uma análise de intervalo de tempo e do conteúdo. Dificuldades típicas à compreensão das alternações e respostas nas transcrições de chats - em concordância com aquilo descrito por outros pesquisadores (Smith et al., 2000) - foram parcialmente superadas com o acompanhamento dos registros online das sessões, para uma melhor interpretação do contexto original da comunicação. Postagens únicas foram consideradas como unidade de análise.Abordagens utilizando unidades mais detalhadas, como orações únicas (ver Oriogun, 2006 e De Wever at al., 2006 para uma revisão da literatura), foram consideradas excessivamente demoradas com relação aos benefícios potenciais que poderiam trazer à pesquisa, e, portanto, não foram adotadas.

Sempre que a simples visualização das postagens em ordem cronológica era considerada insuficiente para codificar as postagens apropriadamente - especialmente com relação à subdimensão da interação entre os participantes -, fez-se referência ao registro audiovisual das sessões, disponível na página da VC. Esse recurso não só permitia aos codificadores saber se as postagens eram comentários ou respostas dirigidas a discursos verbais de moderadores/apresentadores, mas também ter uma ideia do intervalo de tempo que se passava entre a visualização na tela de uma postagem e a postagem seguinte. Dado que é evidente que uma mensagem que aparece na tela um décimo de segundo após a anterior não é resposta direta a ela, essa ferramenta facilitou aos pesquisadores a melhor reconstrução do contexto original da comunicação, superando parcialmente as dificuldades ligadas ao processo de compreensão da sucessão de mensagens e respostas em um ambiente de comunicação quasi-síncrona, no qual as postagens não têm registro de horário detalhado (Smith et al., 2000).

Confrabilidade entre-avaliadores. Após sessões comuns de treinamento, dois ou três pesquisadores codificaram independentemente as transcrições de acordo com a dimensão e as categorias descritas nos parágrafos acima. Ao codificar as postagens de acordo com os estágios de $\mathrm{CT}$, a taxa de concordância entre os pesquisadores variava de $75 \%$ a $96 \%$. Essas porcentagens foram consideradas aceitáveis para a validade interna do estudo (Hara et al., 2000). Discordâncias na codificação eram conciliadas por meio de diálogo verbal até a obtenção de um consenso (Curran et al., 2003; Hara et al., 2000).

A análise quantitativa e qualitativa foi conduzida em todas as sessões das VCs, e os resultados gerais foram descritos por meio de um relatório cumulativo. Contudo, duas sessões de cada VC foram escolhidas para análise aprofundada. Em particular, a relação entre os tipos de perguntas feitas por apresentadores/moderador aos participantes foi analisada, para avaliar se a natureza das perguntas influenciou o desenvolvimento de diferentes níveis de CT, como sugerido pela literatura (MacKnight, 2000; Hara et al., 2000; Bai, 2009).

Ademais, um método de análise estatística - como a tabulação cruzada foi adotado para a potencial identificação de associações entre subdimensões apresentadas na matriz de avaliação. 


\section{Resultados}

Logística. O número total de participantes na VC Mudanças Climáticas

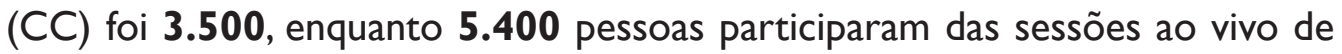
Solução de Problemas com os Especialistas do Smithsonian (PS).

O número total de postagens digitadas pelos participantes durante as duas VCs foi 4.169: mais precisamente, I.I 27 mensagens foram postadas por 462 participantes durante a VC CC, enquanto 3.042 mensagens foram postadas por 434 participantes durante a VC PS.A porcentagem de postagens múltiplas foi calculada em $50,2 \%$ e $60 \%$ respectivamente, o que significa que nos dois eventos online mais da metade dos participantes postou mais de uma vez.

A análise do tipo de comentário (Figura ) abaixo ilustra que a maioria das postagens era bastante complexa. De fato, $49,4 \%$ das postagens foram orações, seguidas por frases $(33,2 \%)$, uma palavra $(13,6 \%)$, combinações $(3,3 \%)$ e pontuações/símbolos $(0,2 \%)$.

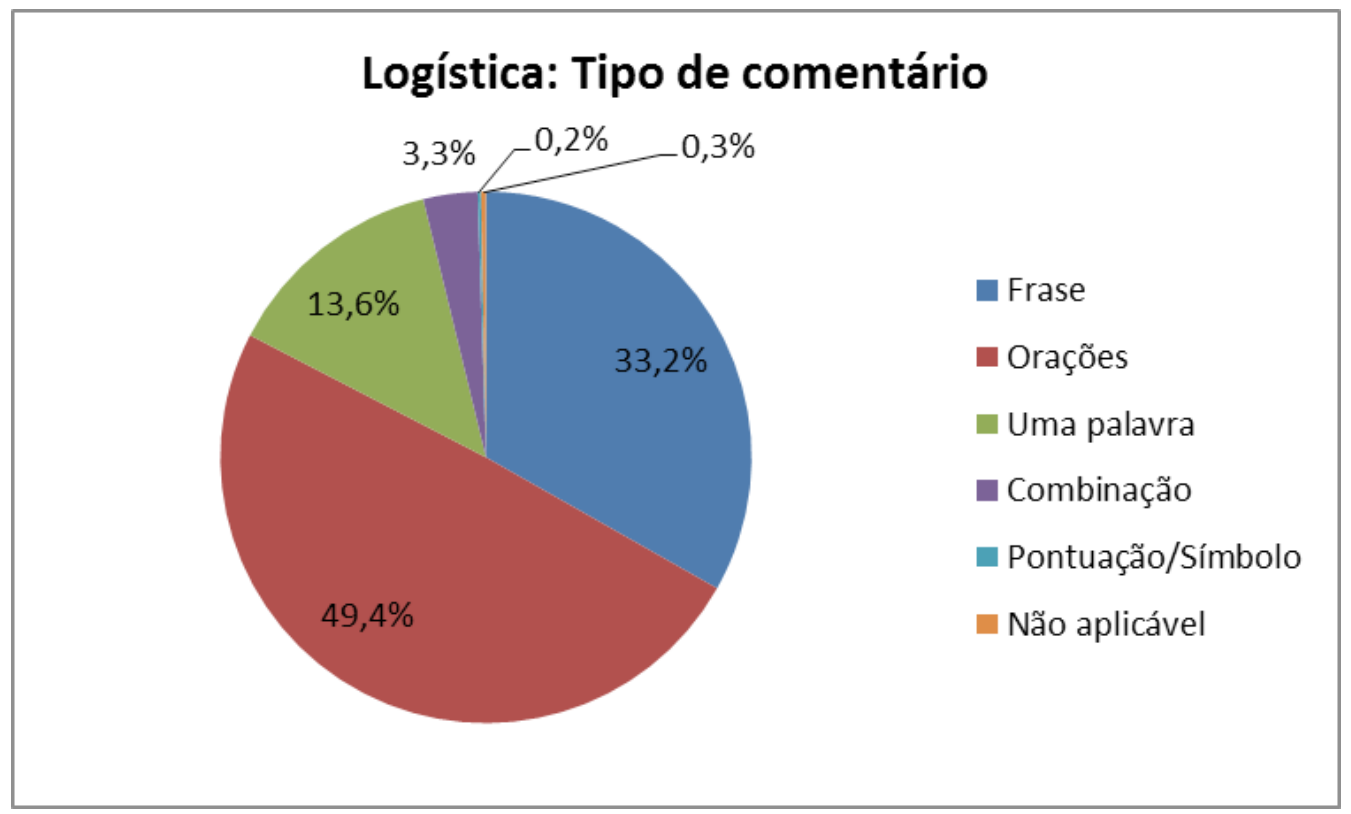

Figura 4. Logística:Tipo de Comentário

Além disso, mais de $80 \%$ das postagens eram relativas ao conteúdo. Mensagens com função social representaram 13\%, enquanto a combinação social/ conteúdo foi identificada em $6,2 \%$ das postagens. Como descrito anteriormente, mensagens técnicas e administrativas foram filtradas em sua maioria pelo moderador: por essa razão, representam menos de $0,5 \%$ das postagens (Figura 5). 


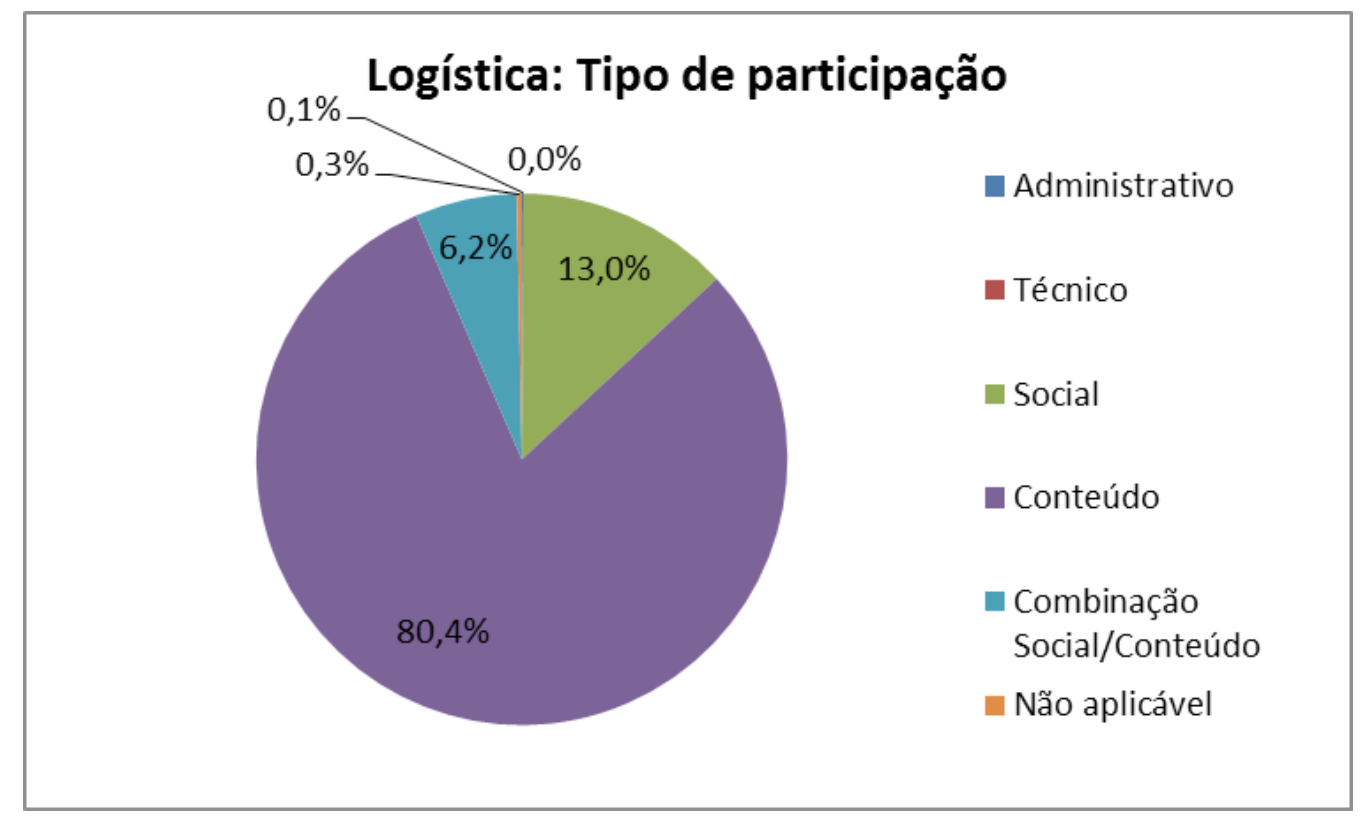

Figura 5. Logística:Tipo de Participação

Análise de conversas: interação. A análise da interação entre participantes que a grande maioria das postagens $(79,3 \%)$ pertencia à categoria Participante para Apresentador, enquanto a porcentagem de postagens de Participante para Participante era somente por volta de 7,I\%. As postagens que refletem os outros tipos possíveis de interação entre participantes/apresentadores/moderador representaram menos de $2 \%$. Para I $3 \%$ das postagens, os codificadores não conseguiram identificar claramente o tipo de interação que ocorreu (Figura 6).

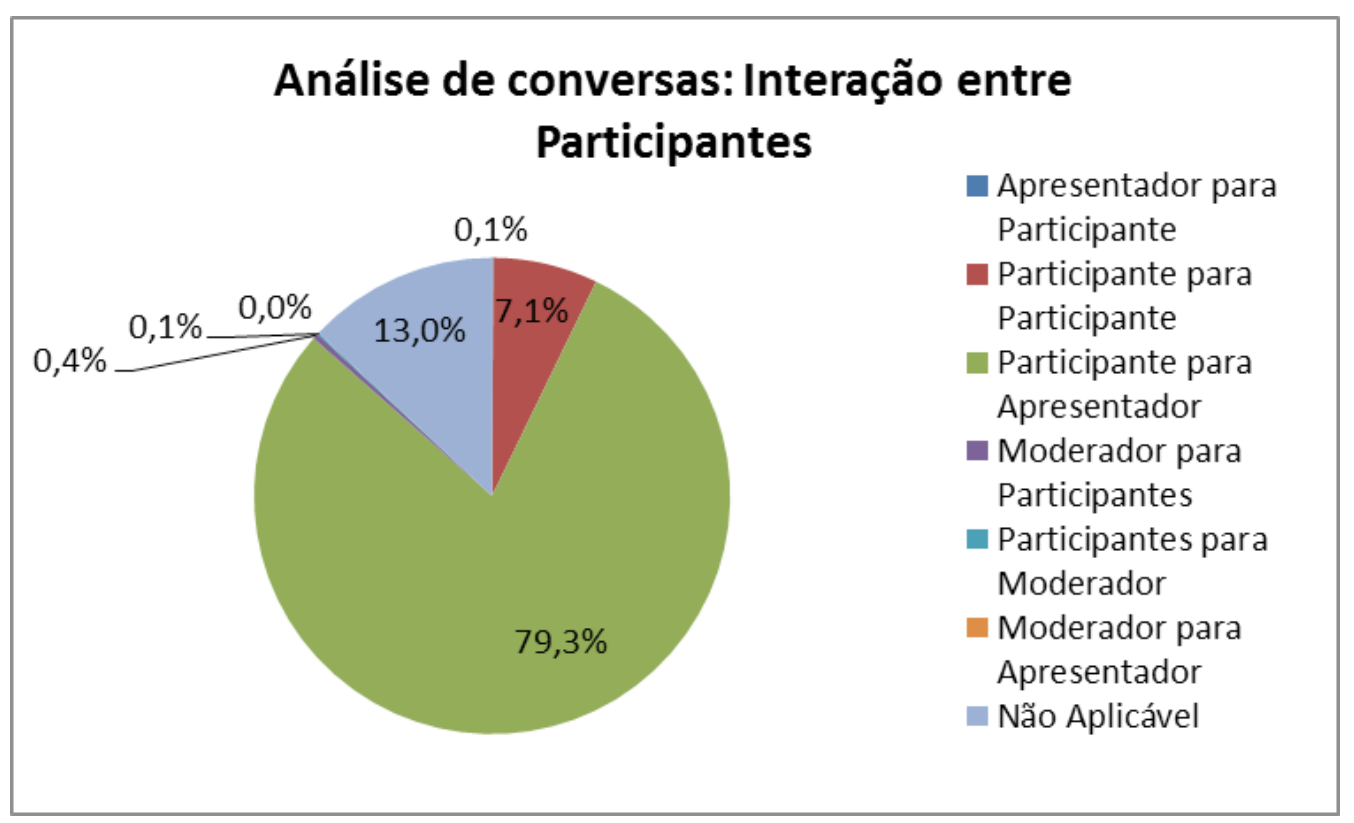

Figura 6.Análise de Conversas: Interação entre os Participantes 
Os dados referentes ao tipo de interação mostram que $54,2 \%$ das postagens foram codificadas como respostas explícitas diretas a uma pergunta feita, enquanto respostas a uma mensagem anterior (Implícita: Resposta Indireta) foram de cerca de 2,5\%. Comentários compuseram entre 4,7\% (Implícita: Comentário Indireto) e 8,2\% (Explícita: Comentário Direto). Mensagens independentes, ou seja, postagens relacionadas ao assunto em discussão mas não referentes a contribuições anteriores foram calculadas em 19,3\% (Figura 7).

\section{Análise de conversas: Tipo de Interação}

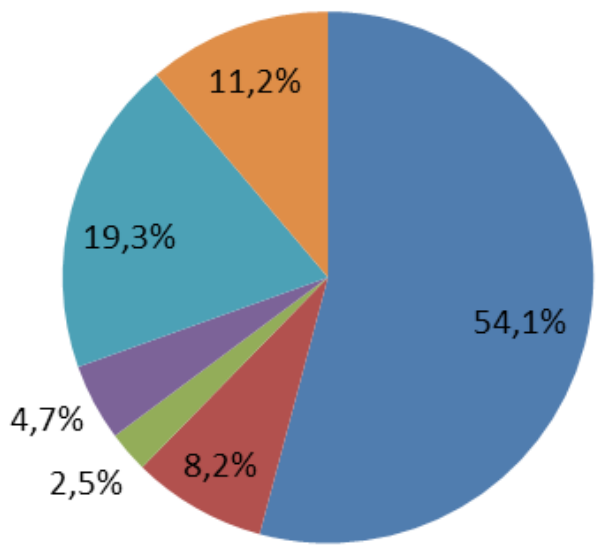

Explícita: Resposta Direta

Explícita: Comentário Direto

Implícita: Resposta Indireta

- Implícita: Comentário Indireto

- Independente

não Aplicável

Figura 7.Análise de Conversas:Tipo de Interação

Coerente com os dados apresentados acima, respostas representaram a grande maioria das postagens $(62,1 \%)$, enquanto postagens originais compuseram 37,9\% (Figura 8).

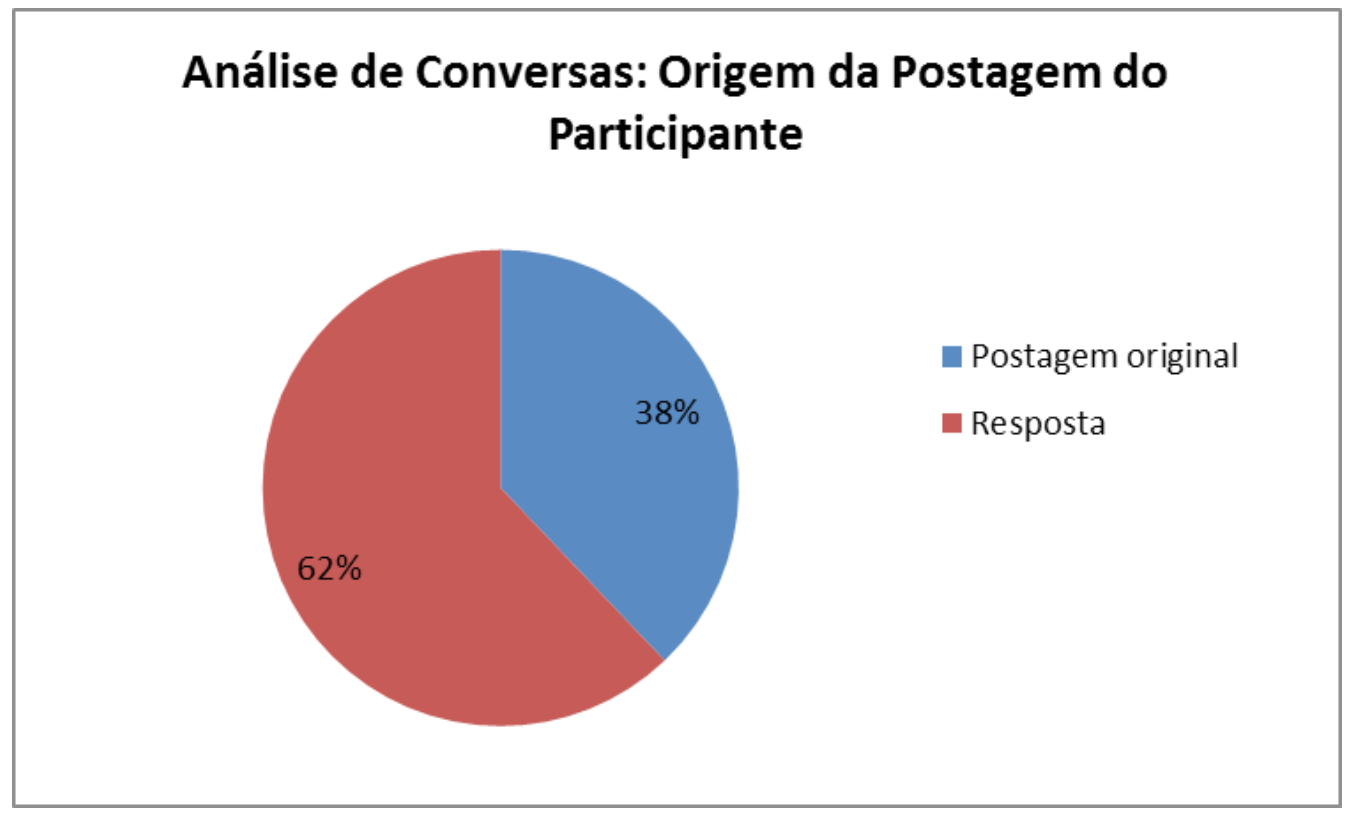

Figura 8. Análise de Conversas: Origem das Postagens dos Participantes 
A tabulação cruzada foi conduzida para identificar possíveis associações entre variáveis. Dado que a investigação da abordagem mind-on utilizada pelos participantes foi considerada especialmente relevante para o estudo, a subdimensão de tipo de participação foi tabulada de forma cruzada com as subdimensões de origem das postagens e tipo de interação.

Os resultados demonstram que o tipo mais frequente de participação relacionado ao conteúdo da $\mathrm{VC}$ foi em grande parte respostas e não postagens originais. Inversamente, a participação de cunho social foi, em sua maioria, original, com muito poucas respostas. Essas descobertas demonstram o papel essencial que o moderador possui no estímulo da aprendizagem e da participação (Figura 9).

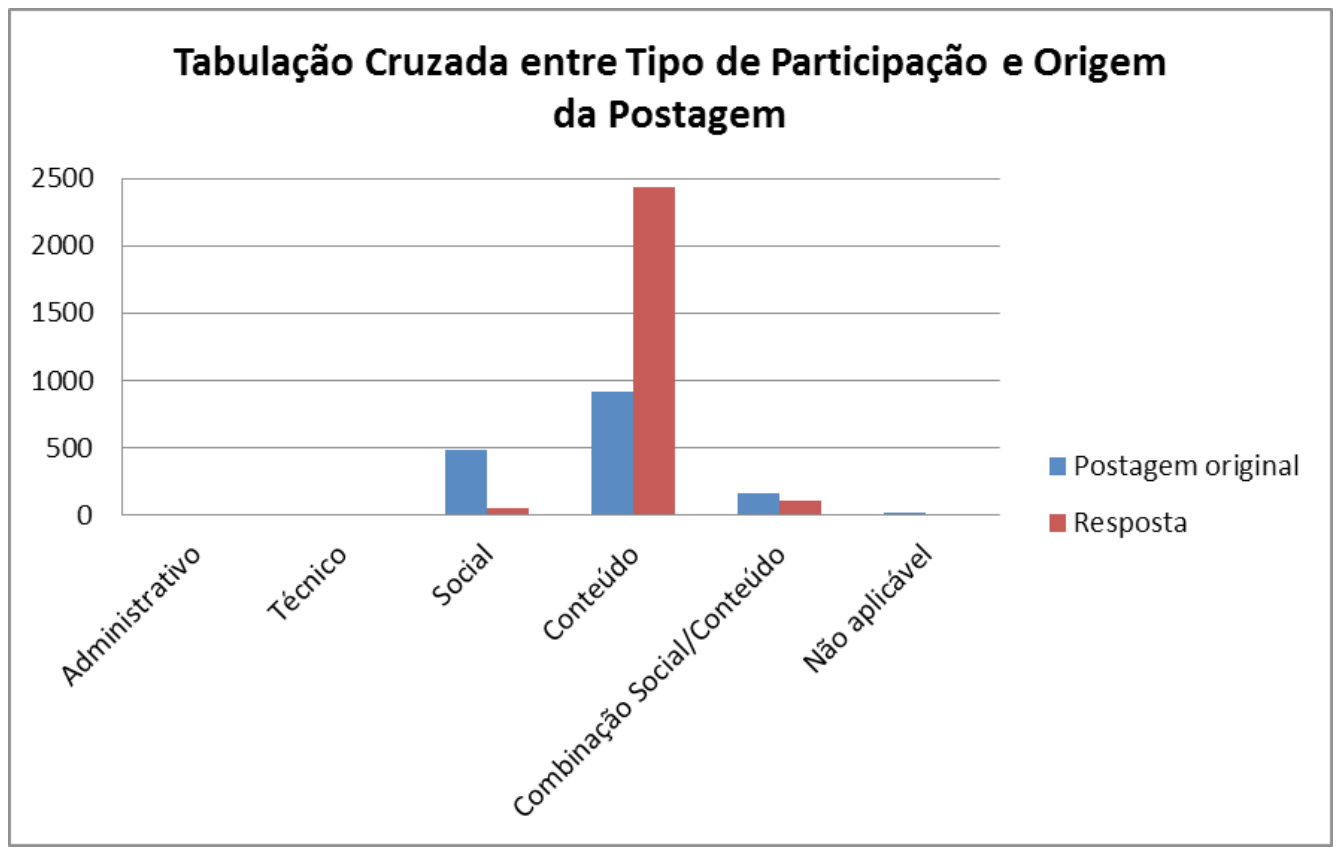

Figura 9. Tabulação Cruzada entre o Tipo de Participação e a Origem das Postagens

Além disso, a maioria das postagens foi Explícita: Respostas Diretas relacionadas ao conteúdo, o que significa que os participantes respondiam a questões relacionadas ao conteúdo apresentadas pelo moderador. (Figura 10)

Análise de conversas: Pensamento Crítico.A análise das subdimensões do CT mostra que a maioria das postagens foi codificada como Clarificação Elementar/ Identificação de Problemas (53,7\%). As categorias de Clarificação de Profundidade/Definição de Problema e Inferência/Exploração de Problema compuseram 13,2\% e 4,2\%, respectivamente. Julgamento/Aplicação de Problema foi identificado em $9,5 \%$ das postagens, enquanto menos de $1 \%$ das postagens pertenciam ao estágio de Estratégia/Integração de Problemas. Finalmente, em 18,9\% das mensagens não foi possível atribuir um estágio específico do CT (Figura II). 


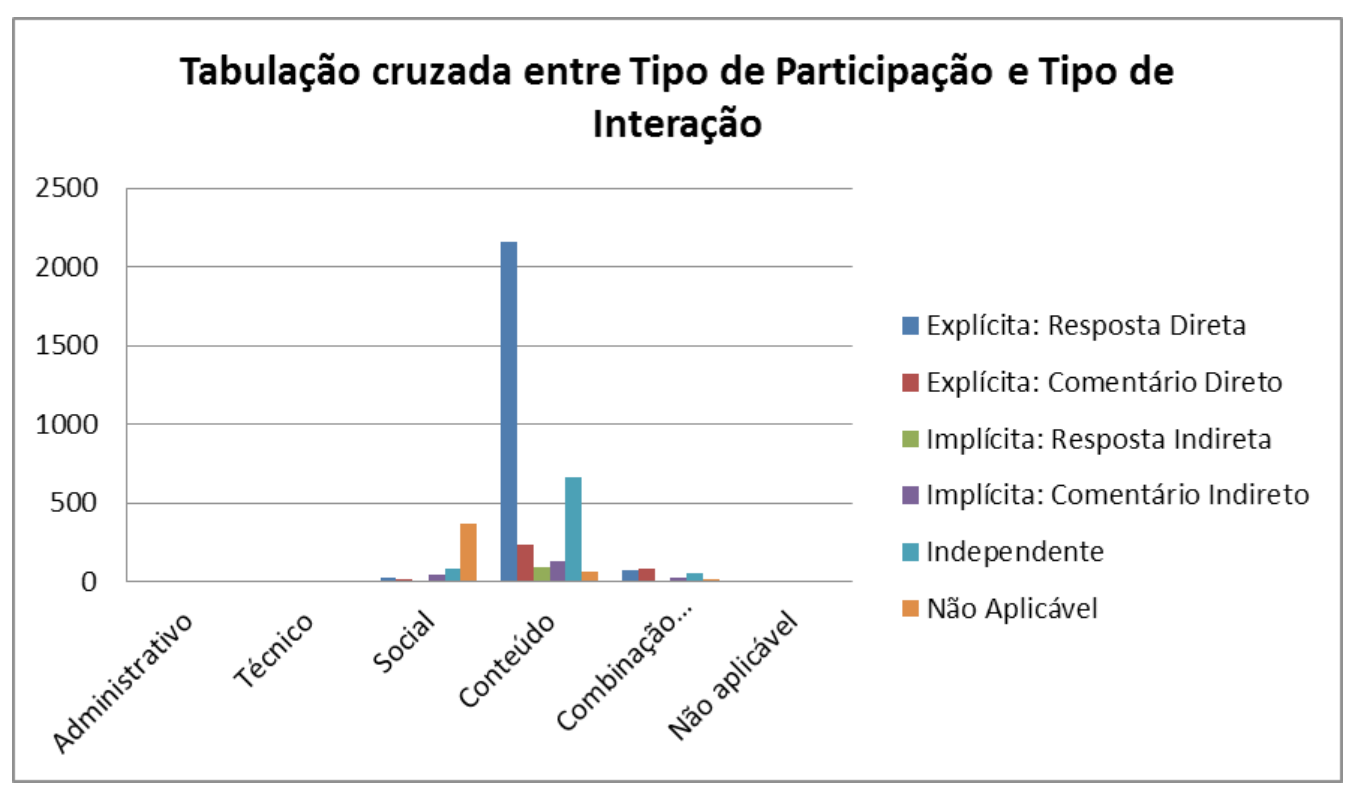

Figura 10.Tabulação Cruzada entre o Tipo de Participação e o Tipo de Interação

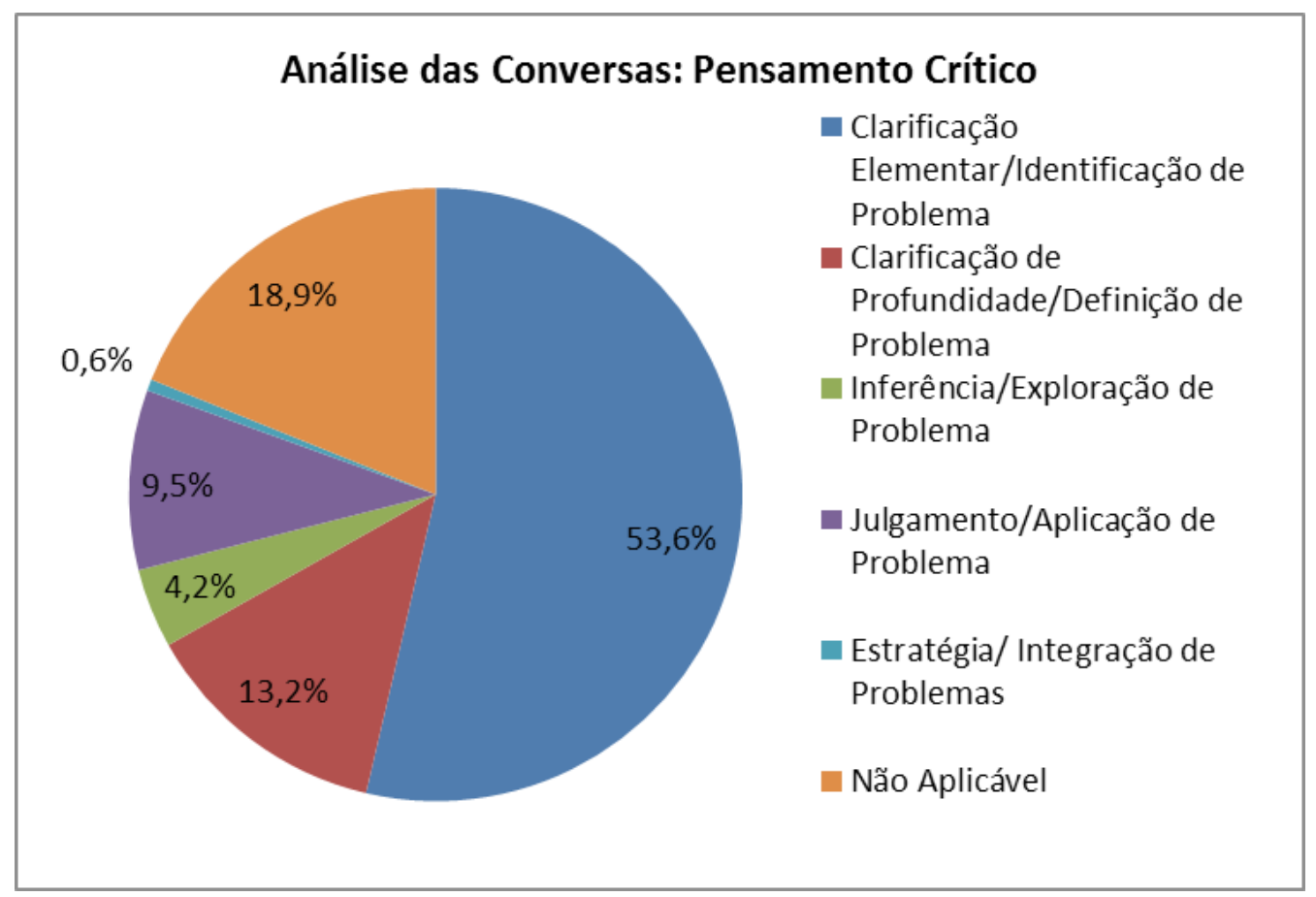

Figura II.Análise de Conversas: Pensamento Crítico 
Com intuito de investigar se diferentes níveis de CT eram estimulados em relação a diferentes tipos de questões propostas por apresentadores/moderador para participantes, foi realizada uma análise em profundidade de quatro sessões selecionadas aleatoriamente. $A$ análise mostrou que altas porcentagens do nível Aplicação de problema/Julgamento surgiram após questões como "Como você está trabalhando para reduzir sua emissão de carbono?” (SR3, Q2), enquanto postagens codificadas como pertencentes à fase Integração de Proble$\mathrm{ma} /$ Estratégia apareceram após questão "Pense sobre como você usa energia em sua casa, trabalho ou escola e pense sobre maneiras para você usar menos energia ou usar com mais eficiência.Você pode pensar em alguma coisa que possa inventar ou você gostaria que um inventor inventasse?" (SR3, Q9). As fases de Clarificação de identificação e Exploração foram encorajadas por meio de questões formuladas como "Você pode identificar o artista bem conhecido nesta fotografia?” (SSSI, QI), “Nós chegamos a um ponto irreversível?” (ESI, Q6), "Inclua o por quê na janela de chat" (SSS2, Q4), respectivamente (Figura I2)

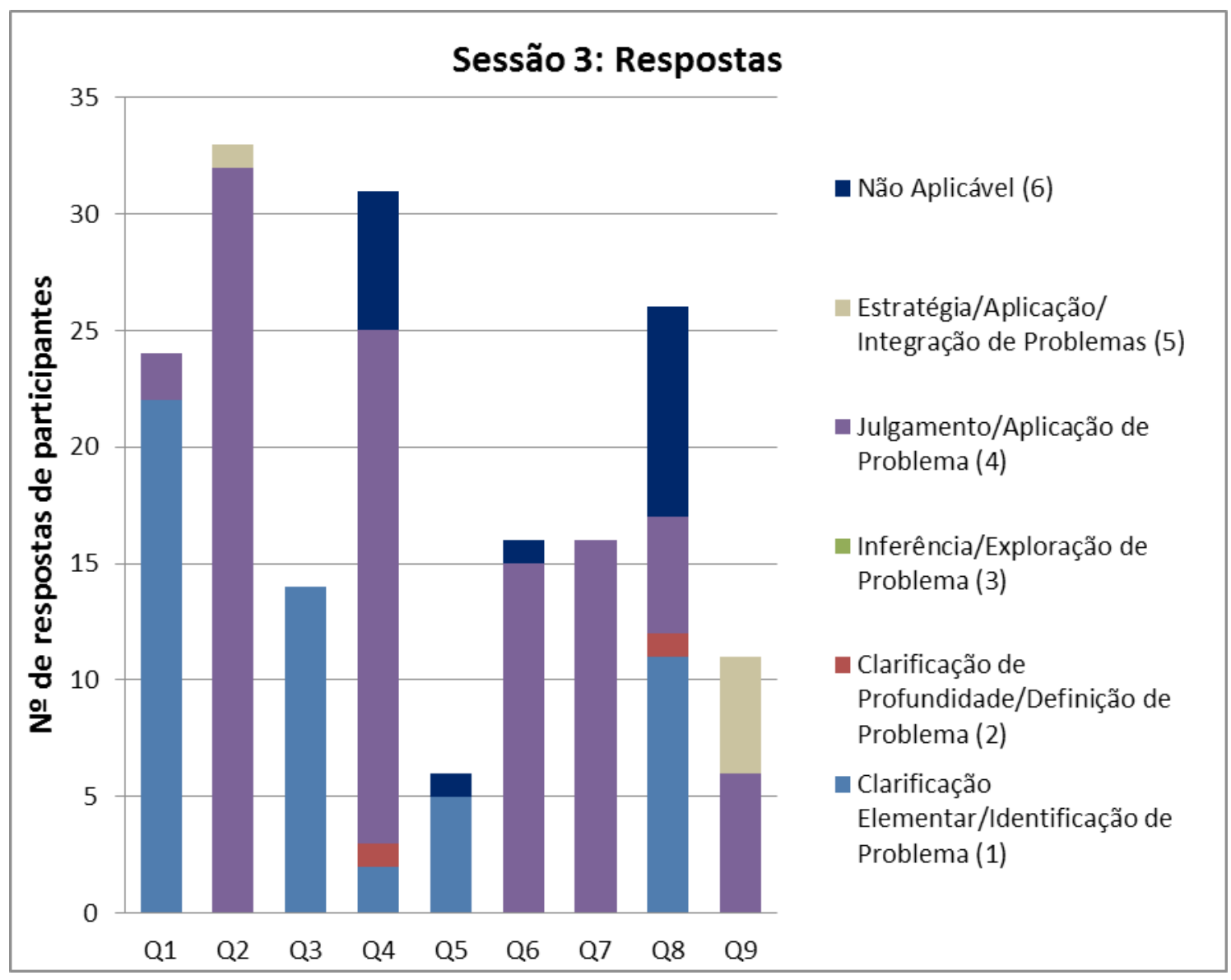

Figura 12. Fases do Pensamento Crítico alcançadas em sessões de questões específicas (Q) na sessão SR3. O gráfico de barras esclarece que diferentes fases de CT foram registradas em relação a diferentes questões. 


\section{Discussão}

Os dados que ilustram a taxa de participação das VCs demonstram que centenas de pessoas participaram ativamente com uma ou mais postagens. Considerando que 3.500 pessoas participaram na VC CC e 5.400na VC OS, e as postagens foram geradas por 462 pessoas para a VC CC e por 434 pessoas para a VC OS, parece evidente que somente uma parte do público usou postagens para participar ativamente nas VCs (13,2\% e $8 \%$, respectivamente). Além disso, se considerarmos que é provável que um número maior de pessoas tenha assistido aos eventos online, por causa da possibilidade de que um usuário conectado estivesse acompanhado ao assistir as VCs, as porcentagens mencionadas acima devem ser interpretadas como sendo ainda menores. As razões por trás desse fenômeno podem ser várias, e a literatura indica que a participação em Comunicação Mediada por Computador (CMC) pode ser limitada por dificuldades de aprendizagem sobre o funcionamento de sistemas de CMC e por razões de privacidade (Curran et al., 2003), mas também por preferências de estilo de aprendizagem (Bullen, 1998). Sobre isso, deve-se lembrar de que "lurkers" [espreitadores, que não contribuem à discussão] existem e que podem preferir não se envolver nas VCs, mas somente observar os comentários e a interação dos outros (Maurino, 2006). Ademais, o fato de que alguns participantes postaram somente uma vez enquanto outros postaram várias vezes mostra que o nível de interação também varia, sugerindo que a autoconfiança e a atitude pessoal quanto à CMC também podem ter um papel.

Os dados relativos ao tipo de comentário mostram que $49,4 \%$ das postagens foram codificados como orações, tendo um sujeito e um verbo: esse resultado deve ser salientado, já que a literatura indica que, pelo contrário, mensagens postadas em ambientes de comunicação síncrona são frequentemente pequenas, sem uma estrutura característica de discurso (Čech \& Condon, 2004). $\mathrm{Na}$ interpretação desses dados, devemos estar abertos à ideia de que o tamanho e a complexidade das postagens foram influenciados pela abordagem minds-on escolhida pelos participantes durante as VCs. Cerca de $80,3 \%$ das postagens eram relacionadas ao conteúdo, enquanto apenas $13 \%$ possuíam funções sociais.

Ademais, os codificadores notaram que mensagens sociais concentravam-se no início e no fim das sessões, representando principalmente os participantes apresentando-se, saudações e expressões de agradecimento. Esse padrão sugere que os participantes estavam concentrados no conteúdo durante as VCs, limitando a expressão se sua presença social aos momentos anteriores e posteriores à apresentação.

A análise das postagens de acordo com a dimensão de interação entre os participantes confirma que o ambiente de VCs não foi percebido pelo público como um espaço para interações sociais. $\mathrm{Na}$ verdade, a grande maioria das postagens $(79,3 \%)$ pertence à categoria Participante para Apresentador, enquanto a porcentagem de postagens de Participante para Participante é só de $7 \%$. Esses dados parecem ser confirmados pelas opiniões colhidas por meio de uma pesquisa conduzida entre os participantes após as VCs. Somente $10 \%$ dos participantes avaliaram a comunicação com outros participantes como um dos aspectos de maior utilidade naVC, enquanto $44 \%$ mencionaram a oportunidade de fazer perguntas aos facilitadores do Smithsonian (Learning Times, 20 I0).

Os dados referentes ao tipo de interação reforçaram as considerações já feitas sobre a interação entre os participantes: mais de $50 \%$ das postagens eram respostas explícitas diretas a perguntas feitas a um apresentador, enquan- 
to respostas a mensagens anteriores eram apenas 2,5\%. Comentários foram menos presentes que respostas, padrão que está em consonância com as baixas porcentagens da categoria de Aplicação de Problemas/Julgamento do CT registradas nas VCs. Mensagens independentes, isto é, postagens relacionadas ao assunto em discussão mas não referentes às contribuições anteriores foram 19,3\%, o que sugere que as VCs estimularam não somente respostas nos participantes, mas também novos pontos para discussão. Coerentemente com esses dados, respostas representaram a grande maioria das postagens $(62,1 \%)$, mas mensagens originais também estavam presentes (37,9\%). A tabulação cruzada entre as subdimensões de origem das postagens e tipo de participação mostrou que as mensagens com função social eram principalmente originais, enquanto postagens relacionadas ao conteúdo eram em sua maioria respostas. Por último, a porcentagem de mensagens sem relação com o tema (I I,2\%) foi, não surpreendentemente, muito similar à registrada para a categoria "social" na dimensão de tipo de participação (I3\%). Sobre esse ponto, a tabulação cruzada entre as subdimensões de tipo de interação e tipo de participação confirmou que, na maioria das postagens com função social, era impossível determinar o tipo de interação que ocorria.

Os resultados obtidos da análise dos níveis de CT parecem confirmar os padrões descritos frequentemente pela literatura que investiga o desenvolvimento do $\mathrm{CT}$ em relação à CMC.Vários autores indicaram que a maioria das postagens - mesmo em ambientes de comunicação assíncrona - normalmente se classifica nas primeiras fases do ciclo de CT (Bai, 2009; Maurino, 2006; Garrison et al., 200I), mostrando uma quantidade mínima de reflexão crítica (Curran et al.. 2003). Ademais, deve ser dito que as mensagens analisadas neste trabalho foram postadas de forma quasi-síncrona, e que esse tipo de comunicação tem sido considerado, geralmente, menos eficaz no estímulo de reflexões que ferramentas de CMC assíncronas (Mason, 1998 apud Armitt et al., 2002), embora a questão ainda esteja em debate, pois alguns autores afirmam que ambas as formas de comunicação são potencialmente valiosas (Lincoln et al., 1997 apud Armitt et al., 2002). Contudo, de forma geral, a comunicação síncrona normalmente é valorizada por seu potencial de permitir esclarecimento imediato (Armitt et al., 2002) e facilitar sessões de brainstorming (Finkelstein, 2006).

As porcentagens pequenas registradas para a Exploração de Problemas, Aplicação de Problemas e Integração de Problemas (categorias 3, 4 e 5) podem ser interpretadas como evidências de que essas fases do processo de CT raramente aconteceram no ambiente de VCs. Para discutir essa questão, deve-se primeiro dizer que um dos limitantes dos estudos que não avaliam o desenvolvimento do $\mathrm{CT}$ utilizando métodos - como testes de conteúdo, avaliações, monitoramento etc. -indicam que o desenvolvimento de diferentes níveis de CT pode não ser percebível para os codificadores somente pela análise das postagens. Como destacado por Garrison (1991), a fase de integração de problemas é especialmente difícil de avaliar, pois representa a adoção de uma ideia no mundo concreto. Ademais, se considerarmos não somente que plataformas de comunicação síncrona geralmente são considerados como encorajadores de um tipo de interação cujo objetivo é clarificação imediata (estágios I e 2), mas também que o principal objetivo logístico das VCs era permitir aos participantes fazer perguntas a especialistas, pode ser possível que não houve facilitação suficiente para permitir aos participantes postar mensagens que refletissem os estágios 3,4 e 5 . 
A análise em profundidade conduzida para quatro sessões sugere que perguntas que estimulem os participantes a dar respostas que envolvam seu conhecimento factual e anterior estão ligadas principalmente aos níveis I e 2 de CT, enquanto perguntas de "por que" e "como", que desafiam os processos de raciocínio dos participantes, podem encorajá-los a escrever postagens que pertencem à fase 4 e mesmo à 5 . Os dados fornecidos parecem então confirmar o que a literatura indica sobre a importância do apresentador/moderador na mediação da discussão e no controle dos níveis de aprendizagem das perguntas (Bai, 2009; MacKnight, 2009; Hara et al., 2000; Bullen, 1998). Como proposto por D. R. Garrison, ambientes eficazes de conferências virtuais baseadas em textos devem ser caracterizadas pela "presença de um educador", valiosa não somente por sua gestão instrucional, mas também por sua capacidade de auxiliar na construção do entendimento (Garrison et al., 2000).

Finalmente, considerando que quase todas as postagens foram endereçadas dos participantes ao apresentador, deve ser dito que não há evidência de que diferentes tipos de interação influenciaram o desenvolvimento de diferentes tipos de CT, e essa área de pesquisa deve ser explorada de maneira mais profunda, através de outros estudos de caso em que os participantes têm uma interação recíproca visível e avaliável.

\section{Conclusões e recomendações}

Conferências virtuais potencialmente representam, para os museus, um meio de envolver as pessoas independentemente de sua localização geográfica, auxiliando-as a concentrar-se em assuntos ou temas específicos e fornecer um ambiente virtual que facilita uma abordagem minds-on. Em outras palavras, VCs podem ser úteis na expansão da missão educacional dos museus fora de seus muros, alcançando pessoas que podem nunca visitar sua localidade física. Contudo, se, por um lado, o sucesso das VCs pode ser atestado por meio da taxa de participação da iniciativa, por outro a medida de sua eficácia com relação à obtenção de resultados de aprendizagem específicos necessita de métodos apropriados, que, idealmente, deveriam ser projetados junto com a idealização do conteúdo, da plataforma e dos objetivos dos eventos online.

Este estudo investigou se as VCs do SCLDA foram eficazes no estímulo ao pensamento crítico. Os resultados mostraram que o ambiente quasi-síncrono de comunicação fornecido pelas VCs facilitou principalmente os primeiros estágios do CT. Ademais, é comumente aceito que o desenvolvimento de níveis mais altos de CT é de difícil mensuração através da análise de conversas em mensagens postadas em um ambiente de comunicação quasi-síncrona.

A análise em profundidade de quatro sessões selecionadas randomicamente sugeriu que os níveis de CT dependem altamente do papel do moderador do evento online. Como consequência, VCs mais eficazes com o objetivo de desenvolver níveis mais altos de CT devem incluir perguntas que convidem os participantes a trazer seus conhecimentos e experiências para a discussão.

Finalmente, este estudo mostrou que os participantes não consideraram o evento online como uma oportunidade de comunicação com outros participantes, preferindo fazer perguntas a especialistas. Dado o pequeno número de postagens de participantes para outros participantes, não foi possível investigar os níveis de CT estimulados pela conversa entre usuários, e pesquisas adicionais nesse campo são necessárias. 
Em especial, se aceitarmos que a aprendizagem é fundamentalmente um processo de significação mediado socialmente (Vygotski, 1978) e que a validação do significado construído pelo aprendiz ocorre pelo compartilhamento de entendimento pessoal com outros (Garrison, I 99I), a disponibilização adicional de uma plataforma que permite comunicação assíncrona poderia auxiliar os participantes a se projetarem socialmente e emocionalmente, sustentando seu envolvimento cognitivo no ambiente de aprendizagem virtual (Garrison et al., 2000).

Segundo os autores, uma avaliação de um ambiente virtual desse tipo deve não somente aproveitar os métodos de análise de conversas apresentados neste estudo, mas também desenvolver indicadores-chave com foco em outros aspectos qualitativos da conversa. Devemos lembrar que aprendizes são interdependentes de outros aprendizes e de facilitadores (Garrison, 1992) e que os participantes "não estão falando no mesmo espaço virtual por acaso, e independentemente da presença dos outros; eles agem em relação um ao outro e de uma maneira que reflete a presença e a influência dos outros. Eles não estão meramente agindo ou reagindo, mas interagindo, mesmo que as ligações entre as mensagens individuais não sejam imediatamente aparentes" (Gunawardena et al., 1997).

\section{Agradecimentos}

Os autores agradecem a Amy Martinez e Leslie Lang, ex-estagiárias do SCLDA, por sua contribuição na análise das postagens das VCs e a Stephen Binns, SCLDA, e Madlyn Runburg, Natural History Museum de Utah, pela revisão crítica do artigo.

\section{Referências}

ARMITT, G., SLACK, F., GREEN, S. \& BEER, M. (2002). The development of deep learning during a synchronous collaborative on-line course. In Proceedings of CSCL 2002, Boulder, Colorado, USA. Lawrence Erlbaum, I5I-I58. Acessado em 20 de outubro de 2010 em http://shura.shu.ac.uk/53/l/fulltext.pdf

BAI, H. (2009). Facilitating students' critical thinking in online discussion: An instructor's experience. Journal of Interactive Online Learning, 8 (2), 156- I64.

BROOKFIELD, S. D. ( 1 987). Developing CriticalThinkers. San Francisco:Jossey Bass. BULLEN, M. (1998). Participation and critical thinking in online university distance education. The Journal of Distance Education, I3 (2), I-32.

CAFFARELLA, R., \& MERRIAM, S. (1999). Learning in Adulthood: a Comprehensive Guide. San Francisco, CA: Jossey-Bass.

ČECH, C. G. \& CONDON, S. L. (2004). Temporal properties of turn-taking and turn-packaging in Synchronous Computer-Mediated Communication. In Proceedings of the 37th Hawaii International Conference on System Sciences. Acessado em 20de Outubro em http://www.computer.org/portal/web/csdl/doi/I0.II09/ HICSS.2004.I 265282

CURRAN, V., KIRBY, F., PARSONS, E., \& LOCKYER, J. (2003). Discourse analysis of computer-mediated conferencing in world wide web-based continuing medical education. The Journal of Continuing Education in Health Progessions, 23, 229-238.

D'ANGELO, E. (197I). The Teaching of Critical Thinking. Amsterdam: B. R. Gruner. 
DEWEY, J. (1933). How We Think. Boston: D. C. Heath.

DE WEVER, B., SCHELLENS, T., VALCKE, M., \& VAN KEER, H. (2006). Content analysis schemes to analyze transcripts of online asynchronous discussion groups:A review. Computers and Education, 46, 6-28.

DI BLAS, N. \& POGGI, C. (2006). 3D for Cultural Heritage and education: evaluating the impact. In J. Trant and D. Bearman (Eds.). Museums and the Web 2006: Proceedings, Toronto:Archives \& Museum Informatics.Acessado em 20 de outubro de2010 em http://archimuse.com/mw2006/papers/diblas/diblas.htmlFINKELSTEIN, J. (2006). Learning in Real Time: Synchronous Teaching and Learning Online. San Francisco, CA: Jossey-Bass.

GARRISON, D. R. (I99I). Critical thinking and adult education: a conceptual model for developing critical thinking in adult learners. International Journal of Lifelong Education, 10, 287-303.

GARRISON, D. R. (1992). Critical thinking and self-directed learning in adult education: an analysis of responsibility and control issues. Adult Education Quarterly, 42 (3), I 36-I 48.

GARRISON, D. R., ANDERSON, T., \& ARCHER, W. (2000). Critical thinking in a text-based environment: computer conferencing in higher education. Internet and Higher Education, II, I-I4. Acessado em 20 de outubro de 2010 em http:// communitiesofinquiry.com/documents/CTinTextEnvFinal.pdf

GARRISON, D. R., ANDERSON, T., \& ARCHER,W. (200I). Critical thinking, cognitive presence, and computer conferencing in distance education. American Journal of Distance Education, 15, 7-23. Acessado em 20 de outubro de 2010 em http://communitiesofinquiry.com/documents/CogPresPaper June30 .pdfGUNAWARDENA, C. N., LOWE, C.A., \& ANDERSON, T. (1997). Analysis of a global online debate and the development of an interaction analysis model for examining social construction of knowledge in computer conferencing. Journal of Educational Computing Research, I7, 397-43I.

HARA, N., BONK, C.J., \& ANGELI,J. (2000). Content analysis of online discussion in an applied educational psychology course. Instructional Science, 28, I I5- I 52.

HENRI, F. (1992). Computer conferencing and content analysis. In A. R. Kaye (Ed.), Collaborative learning through computer conferencing. The Najadan Papers, I I 7- I 36. London: Springer-Verlag.

HOOPER-GREENHILL, E. (2007). Museums and Education: Purpose, Pedagogy, Performance. New York: Routledge.

KELLY, L. (2009). The impact of social media on museum practice. Paper presented at the National Palace Museum, Taipei, 20th October 2009. Acessado em I5 de novembro de 2010 em http://australianmuseum.net.au/Uploads/Documents $/ 9307 /$ impact\%20of\%20social\%20media\%20on\%20museum\%20practice.pdf Learning Times (2010). Summary of evaluation results Climate Change online conference. Relatório não publicado.

LINCOLN, M., STOCKHAUSEN, L. \& MALONEY, D. ( 1 997) Learning Processes in Clinical Education. In McAllister, L., Lincoln, M., McLeod, S. \& Maloney, D. (Eds), Facilitating Learning in Clinical Settings, 99-I29. Cheltenham: Stanley Thornes.

LOPEZ X., MARGAPOTI, I., MARAGLIANO, R. \& BOVE, G. (20I0). The presence of Web 2.0 tools on museum websites: a comparative study between England, France, Spain, Italy and the USA. Museum Management and Curatorship, 25 (2), 235-249 . 
MASON, R. (1998). Globalising Education:Trends and Applications. London: Routledge. MAURINO, (2006). Looking for Critical Thinking in Online Threaded Discussions. E-Journal of instructional Science and Technology, 9 (2). Acessado em 20 de outubro de $2010 \mathrm{em}$ http://www.ascilite.org.au/ajet/e-jist/docs/vol9_no2/ papers/full_papers/maurino.pdf

MACKNIGHT, C.B. (2000). Teaching critical thinking through online discussions. Educause Quarterly, 4, 38-4I.

MCKENZIE,W., \& MURPHY, D. (2000). “I hope this goes somewhere”: Evaluation of an online discussion group. Australian Journal of Educational Technology, I 6 (3), 239-257.

MCPECK, J. E. (198I). Critical Thinking and Education. Oxford: Martin Robertson. MONACO, P. \& MOUSSOURI,T. (2009).A conversation about intended learning outcomes. Curator, 52 (4), 317-326.

National Science Foundation, (2008). Fostering Learning in the Networked World:The Cyberlearning Opportunity and Challenge. A 2 I st Century Agenda for the National Science Foundation Report of the NSF Task Force on Cyberlearning. Acessado em 20 de outubro de 2010 em http://nsf.gov/pubs/2008/ nsf08204/nsf08204.pdf

NEUENDORF, K.A. (2002). The content analysis guidebook. Thousands Oaks, CA: Sage Publications.

NEWMAN, D. R., JOHNSON, C., COCHRANE, C. \& WEBB, B. (1996). An experiment in group learning technology: evaluating critical thinking in face-to-face and computer-supported seminars, Interpersonal Computing and Technology 4 (I). Acessado em 20 de outubro de 2010 em <http://jan.ucc.nau.edu/ ipct-j//996/ $\mathrm{nl} /$ newman.htm/contents.htm>.

PEKARIK, A. J. (20I0). From knowing to not knowing: moving beyond "outcomes". Curator, 53 (I), I05-II5.

PERKINS, C., \& MURPHY, E. (2006). Identifying and measuring individual engagement in critical thinking in online discussions:An exploratory case study. Educational Technology \& Society, 9 (I), 298-307. Acessado em 20 de outubro de 2010 em http://www.ifets.info/journals/9_//24.pdf.

SMITH, M., CADIZ, J. J., \& BURKHALTER, B. (2000). Conversation trees and threaded chats. In Proceedings of the 2000 ACM conference on Computer supported cooperative work. Acessado em I5 de novembro de 2010 em http:// www.connectedaction.net/wp-content/uploads/2009/08/2000-CSCW-Conversation-trees-and-threaded-chats.pdfSPROULL, L. \& KIESLER, S. ( 1986). Reducing social context cues: Electronic mail in organizational communication. Management Science, 32, |492-15 I2.

VYGOTSKY, L. S. (1978). Mind in society: The development of higher psychological processes. Cambridge, MA: Harvard University Press. 
$\underline{186}$

究

ษั

先

䒕

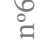

$\exists$

띨

客

z

붕

翔

$\infty$

嵌

至 